\title{
Smog in China and selling of pure oxygen
}

\begin{abstract}
Chinese economy is one of the strongest of today's world. It is also a major contributor to global Green House Gas (GHG) emission. The projected hike in GHG emission in 2030 is $26 \%$. A number of city of Chinese territory is now facing the severe smog pollution. This also poses serious threat to the health of its citizen. The severity of this issue leads to the creation of new business scheme of selling oxygen by the outsiders. This viewpoint analyses the present scenario of smog and some probable measures that can be initiated to combat the problem.
\end{abstract}

Keywords: smog, ghg, air pollution, china, green house, carbon monoxide

\author{
Volume 2 Issue 2 - 2017
}

\author{
Kamrul Islam \\ Institute of Forestry and Environmental Sciences, University of \\ Chittagong, Bangladesh
}

Correspondence: Kamrul Islam, Institute of Forestry and Environmental Sciences, University of Chittagong, Bangladesh, Email ksujonifescu@gmail.com

Received: February 17, 2017| Published: February 23, 2017

\section{Why is the problem?}

China is considered the strongest nation based on its economy. This cherished economy is not the gift of God rather it is possible by altering the God gifted natural resources of it. By doing so, a tremendous pressure is continually being exerted on the environment of Chinese territory. It has already overtaken the other mighty nation - the US with respect to GHG (Green House Gas) emission. Despite serious efforts that have been made to shift the energy mix in favor of non-fossil fuels, as of 2011, China still requires 50\% higher energy intensity than the US. China's proportion of global GHG emissions is projected to rise from $17 \%$ in 2005 to $26 \%$ in 2030 , reaching $16.664 \mathrm{Gt}$ $\mathrm{CO}_{2} \mathrm{e}$. The dependency of coal and use in enormous amount is the single dominant cause of the so called Smog pollution in China.

Air pollution is a severe problem that can affect our health and economy. It is found now-a-days that smog floats heavily over Beijing, Shanghai and Hong Kong, and children of these three cities grow up with different respiratory problems. The most important concern is $\mathrm{PM}_{2.5}$ (particles with an aerodynamic diameter less than $2.5 \mu \mathrm{m})$ pollution. $\mathrm{PM}_{2.5}$ concentration levels in Beijing, Shanghai, Guangzhou and Xi' an, exceed World Health Organization (WHO) air quality guidelines. This poses higher health risks to the people and ultimately in economy.

Today the major big cities of it are severely facing the issue of smog. The first ever red alert was issued during the late of 2015. The air quality index of that time was 250 and interpreted as very unhealthy being 10 times higher than the World Health Organization's (WHO) recommended level. People of major industrialized cities of China are now seen wearing a masking while in the roadside. The air quality level is so mean that people in some areas are now using oxygen bottle to have some puffs when feel uncomfortable. Understanding the severity of this issue, several companies (mainly Canadian and British) started business of selling pure oxygen. This is indeed adding a new dimension to think about the economics of environmental goods and services as it was considered mostly free of cost to the mass.

\section{Solution}

People are taking oxygen puff not for all the time rather when they feel less comfort. This is really not desired at all. So what can be the probable solution of it? Of course there may be solution for it, but it should be kept in mind that reaching the desired position needs long term planning and effort. The dependency of coal needs to be reduced at time gross domestic product should also be kept in the current pace. This is really a tough job to be done. Another important thing is the increasing demand of steel usages. Alternative of it should be sought for. These are some of the hard line that can be followed. Apart from it, the country can be opt for some other aspects through using the knowledge of resource economics. Different mechanism is available for combating pollution. Economic intensives can be provided to the industries who will keep the pollution level behind the optimum level. Again imposing taxation can be another option also.

An investment of $\$ 215$ billion may reduce the severe pollution problem and save invaluable lives. Although $\$ 215$ billion is of course not a small amount, but it becomes negligible when compared to the effect of air pollution on the Chinese economy. It is estimated that health impacts and lost labor productivity of China is worth $6.5 \%$ of its GDP. Applying that figure to China's 2012 GDP of $\$ 8.2$ trillion implies that reducing air pollution in China to levels considered acceptable by WHO would yield annual benefits of more than $\$ 500$ billion.

The country should commit to the more costly step of shutting down half of its coal-fueled power plants and replacing them with carbon emitting electricity generation technologies that greatly depend on natural gas, nuclear, and other renewable for energy. These are some of the probable solutions that can be followed.

\section{Planning}

Planning for the reduction of smog from Chinese urban area is a difficult task. Long term planning regarding it can provide better result. The country should replace coal with natural gas and within next 10 years and onwards it should reduce the use of coal to $50 \%$. Renewable energy might be used in the production system to run the GDP at its current trend. Older highly pollution motor vehicles should be replaced with modern new one - capable of low emission from it. There are currently more than 14 million vehicles on the road in China that have rudimentary pollution control equipment or none at all. Research suggests that scrapping such vehicles in 2009 would have eliminated $70 \%$ of carbon monoxide, $70 \%$ of volatile hydrocarbons, $61 \%$ of nitrogen oxides, and $76 \%$ of particulate matter emitted by automobiles in China in that year. The one-off costs of scrapping highly polluting vehicles could run $\$ 21$ billion to $\$ 42$ billion.

China is in a tricky position as it needs to balance its natural resource constraints with its economic growth. That means staying away from shorter-term, more narrowly focused solutions like synthetic natural 
gas from coal. Rather, China should look toward long-term strategies like pursuing more environment friendly measures in the air pollution control scheme like industrial restructuring and energy efficiency techniques. Both can significantly reduce energy demand while avoiding water-intensive projects. After all, water and energy security are critical components of long-term economic growth.

\section{Suggestion}

a. Adopting better coal generation technology which causes less emission.

b. Commercial extraction and use of natural gas.

c. Emission abatement while steel and iron production.

d. Continued investment and development of carbon capture and sequestration technology could provide long term mitigation of carbon emissions from coal generated electricity.

e. The Chinese government should relax rigid electricity market structures that reduce incentives to invest in renewable technologies.

f. Adopt scrap steel collection programs and electric arc furnace subsidies.

\section{Acknowledgements}

None.

\section{Conflict of interest}

The author declares no conflict of interest. 